\title{
From Analysis to Synthesis: Conceiving a Transformative Metaphysics for the Twenty-first Century
}

\author{
Mikhail Epstein
}

\author{
Part I: How to Move from Analysis to Synthesis ${ }^{1}$
}

\subsection{Is Analysis a Goal in Itself?}

It is well known that in philosophy, especially of the English-speaking world, the analytical approach has been predominant for about a century. Critical analysis is directed mostly at the logical structure of language as well as at concepts, definitions and propositions. Bertrand Russell, one of the founders of analytic philosophy, states: "One purpose that has run through all that I have said, has been the justification of analysis, i.e., the justification of logical atomism, of the view that you can get down in theory, if not in practice, to ultimate simples, out of which the world is built."2 Robert Ammerman clarifies this assessment: "To analyze, we may say roughly, is to take apart in order to gain a better understanding of what is being analyzed... The philosopher ... is interested in analyzing linguistic or conceptual units. He is concerned, in general, with coming to understand the structure of language by a careful study of its elements and their interrelations. We will use the word 'analysis' (or 'analytic philosophy'), then, to refer to any philosophy which places its greatest emphasis upon the study of language and its complexities." ${ }^{3}$

What would be, then, the place of the synthetic approach in contemporary philosophy? In fact, it is practically never discussed or even mentioned, though analysis and synthesis are known to be correlative procedures. The one-sided development of analysis at the expense of synthesis is a huge loss for philosophy, which has therefore been divested of much of its creative, constructive potential.

1 I am grateful to John Michael Corrigan, an Associate Professor of American Literature and Digital Humanities at National Chengchi University, Taipei City, Taiwan, for his help in editing this article.

2 The Philosophy of Logical Atomism. Cited in Robert Ammerman, ed., Classics of Analytic Philosophy. (Indianapolis and Cambridge: Hackett, 1965), 26.

3 Robert Ammerman. A Short History of Analytic Philosophy, in Robert Ammerman, ed., Classics of Analytic Philosophy. (Indianapolis and Cambridge: Hackett, 1965), 2. 
Bertrand Russell suggested that philosophical analysis should conclude with a synthesis: "The business of philosophy, as I conceive it, is essentially that of logical analysis, followed by logical synthesis."4 But analytic philosophy, as a rule, does not reach the point of synthesis, stopping at the stage of disintegration of the whole and ignoring the task of its re-creation from the parts. The analysis divides judgments into subjects and predicates, syllogisms into premises and conclusions, sentences into words and then morpheme-and the thinker then examines the primary units, the logical atoms of these constructions. This is an important, but preliminary stage of philosophical work, which then must proceed to the synthesis of new concepts and judgments that are different from those initially given and are formed only by the constructive recombination of their elements.

Alexander of Aphrodisias, the authoritative commentator on Aristotle's Analytics, indirectly foresaw the possibility of Synthetics when he wrote: "For analysis is the converse of synthesis. Synthesis is the road from the principles to those things that derive from the principles, and analysis is the return from the end to the principles..." ${ }^{5}$ In other words, synthesis is a progressive vector in the being of things, towards their goal, while analysis is a regress to the primary elements of which things are composed.

Sometimes a synthesis is understood only as an inverse procedure in relation to analysis: by dividing a concept or a judgment into elements, we then derive the same original concept out of them to demonstrate the correctness of the analysis, to prove that the concept is composed of the same elements to which it was divided. But this is a very limited, reductionist understanding of synthesis as just a test or proof of analysis. Such a synthesis does not produce anything new, but only returns to the known, to that original given, from which the analysis departed.

Meanwhile, the task of philosophical synthesis, as I understand it, is the creation of new concepts, terms, ideas, judgments, principles, and also more comprehensive conceptual unities: theories, disciplines, attitudes, and worldviews. Philosophical synthesis requires analysis, but it does not come down to it, to the original concept, but creates the possibility of new, alternative concepts. If the analysis, according to Russell, leads from the known to the unknown, the

4 Bertrand Russell, Logical Atomism (1924) // Bertrand Russell, Logic and Knowledge: Essays 1901-1950 (London: George Allen and Unwin, 1956), 341.

5 Alexander of Aphrodisias. Commentary on Aristotle's Prior Analytics, §1.2.1. Cited in Stanford Encyclopedia of Philosophy. https://plato.stanford.edu/entries/analysis/sı.html\#Alexander. 
synthesis leads from the existing to the not yet existing. Synthesis is an act of thinking that becomes an event of being.

Immanuel Kant's division of judgments into analytical and synthetical is fraught with a criticism of analytical philosophy, which overuses analytical judgments and thereby pushes philosophy to tautologism, i.e. turns thinking into a chain of clarifying, but equivalent, synonymous variations like: "all bodies are extended," "gold is yellow,” or “'do not kill' means 'I condemn murder.” Kant's criticism is worth reading in full:

Analytical judgments express nothing in the predicate but what has been already actually thought in the concept of the subject, though not so distinctly or with the same (full) consciousness. When I say: "All bodies are extended," I have not amplified in the least my concept of body, but have only analyzed it, as extension was really thought to belong to that concept before the judgment was made, though it was not expressed. This judgment is therefore analytical. ${ }^{6}$

Synthetical judgments, on the contrary, amplify the concept and add something which is not already contained in it. Synthesis is not a repetition of the analysis in reverse order, from elements to the whole, but it is the formation of a new whole through the rearrangement of the initial elements, which constitutes the very act of thought. Even if we narrow the subject of philosophy to language, then the measure of intellectual productivity would be to expand the existing language, synthesize new words and concepts, lexical and conceptual fields, introduce new grammatical rules, and increase the scope of the spoken and, therefore, of the potentially thinkable and doable.

\subsection{Problematization as a Transition from Analysis to Synthesis}

Why is the transition from analysis to synthesis logically so difficult that analytical philosophy rarely grows into a synthetic one? The point is that synthesis is not a direct continuation of analysis, but a turning point of thinking that is now moving in the opposite direction, from parts to the whole. A key role in this turn is played by a logical operation that can be called problematization. Each element, deduced from the original concept, is problematized as one in the row of the possible elements that can replace it. It is a way to defamiliarize common sense that is so prone to tautologies. By problematizing the analytically

6 Immanuel Kant, Prolegomena to Any Future Metaphysics https://books.google.com/books? $\mathrm{id}=$ WAw3 3 DAAAQBA J\&pg=PA785\&lpg=PA785\&dq. 
isolated elements and replacing one of them with another element, we get a different concept (judgment, rule) that expands the domain of the thinkable.

We can understand the limitations of analytical judgement very clearly by considering a well-known example proposed by Kant: "All bachelors are unmarried." The very concept of a bachelor is formed by a combination of these two elements: "man" and "unmarried." If we just reconnect them, we get back to the original concept: an unmarried man is a bachelor. Synthesis without problematization does not add anything to the analysis, but only confirms its validity. Such is the tautological interchange between analysis and synthesis, if they are not mediated by problematization.

But let us expand the possibilities of such an analytical judgment by asking: in what sense is a man "unmarried"? Is he unmarried in fact—or out of principle, because he is opposed to marriage and does not want to be bound by marriage? Or perhaps there are certain physical or social conditions that prevent him from marriage? Then it would be more appropriate to use another participle: unmarriable. The lexical system of language requires a new unit: "unmarriable" - the one who does not marry out of principle, because he is unable or unwilling to marry, essentially "unpaired," "incompatible," not designed for family life. This is the simplest example of a synthesis produced on the basis of analysis, when one of its elements, "unmarried," is problematized and supplemented by the alternative term "unmarriable." It turns out that the word "bachelor" can have two different meanings, i.e. point to the two different human types. The analytical judgment that "all bachelors are unmarried" now can be supplemented with a synthetic one: "some bachelors are unmarriable."

For example, the tragicomic element of Dostoevsky's Idiot consists in the fact that two beautiful women compete for Myshkin, wanting to marry him, while he is in principle unmarriable, which he himself states at the beginning of the novel. This is the simplest example: the transition to the synthesis of new judgments through the analysis and problematization of trivial judgments. Similarly, another element of this analytical judgment can be subject to problematization: "man." What if it is a homosexual, or transgender, or nonbinary subject? Can we say that the absence of a permanent or legally registered partner makes them bachelors? Are the very terms "married" or "unmarried" applicable to them? Such problematization opens a new space for synthetic thinking which is now in growing demand due to ethical, psychological, legal, and political concerns about gender issues.

As we see in this example, synthetic operations that arise on the basis of even a trivial analytic proposition are far from trivial and help to enrich the language of thinking. But they are triggered only by problematization, and this 
is the main stumbling block in the transition from philosophical analysis to synthesis. Analysis, brought to the smallest logical atoms, turns out to be intellectually trivial, if these atoms are devoid of movement, "vibrations" and their positions in the logical structure are fixed and irreplaceable. The problem of analytical philosophy is that it is insufficiently problematic; it does not question those elements that are obtained from the analysis of a judgment. This problem can only be solved by the problematization of analysis itself as a philosophical method, offering an alternative to it and showing that problematization itself forms the crucial moment in the transition from analysis to synthesis.

\subsection{Examples of Philosophical Synthesis: Concept, Judgment, Rule, Discipline}

Now I will provide several examples of such a triple operation: from analysisthrough problematization - to synthesis. I will consider synthesis on four rising levels of thinking: concept, judgment, rule, discipline.

1. Synthesis of the concept: infinition. Analytical philosophy likes to use clear definitions, and "definition" is one of its main terms. From the analytical point of view, the definition consists of definable and defining (definiendum and definiens), between which the relation of semantic equivalence is established. But what if this equivalence cannot be established within a definition? Are all concepts definable? Can the definition itself include a moment of selfcriticism, i.e. point to the indeterminateness of this concept?

By problematizing this "definition," we come to a new, alternative notionthe infinition. This term is a blend of two words, definition and infinity originating from one Latin root finis, the end, the limit: Definition is the definition of what is definable. Infinition is the definition of what is undefinable.

Infinition is an infinitely deferred definition that demonstrates the multiplicity of possible definitions and simultaneously the inadequacy of each of them and the impossibility of a complete definition as such. Infinition is an incomplete and unfinalizable definition, an infinite process of defining something that cannot be fully or precisely defined, an endless list of possible definitions.

The term infinition is an example of a linguistic synthesis based on the analysis of the concept of definition:

a. The starting point, thesis: definition is a concise description or explanation of the meaning of a word, term, or concept.

b. Analytical dissection, or logical bifurcation: a word or a concept can be definable or indefinable, i.e. not capable of being precisely described.

c. Synthesis: infinition is a definition of something that is indefinable. 
Certain fluid concepts in their emergent state are subject to infinition -infinite dispersal of their meaning - rather than to definition. We can find many examples of infinition in philosophy and religious thought. They abound in the writings of Lao Tzu, Chuang Tzu and other Taoist thinkers; in the treatises of Pseudo-Dionysius the Areopagite and apophatic theology; and in the works of Jacques Derrida and other followers of deconstruction.

For example, Lao Tse never gives a definition of Tao, but only multiple infinitions: "The Tao that can be trodden is not the enduring and unchanging Tao. The name that can be named is not the enduring and unchanging name" (The Tao Te Ching, Ch. 1, 1-2). Pseudo-Dionysius the Areopagite offers infinitions of the Cause of Everything: "We therefore maintain that the universal and transcendent Cause of all things is neither without being nor without life, nor without reason or intelligence; nor is it a body, nor has it form or shape, quality, quantity or weight" (Mystical Theology, Ch. 4). Jacques Derrida never defines his method of deconstruction, but only infines it: "What deconstruction is not? Everything of course! What is deconstruction? Nothing of course!" "Letter to a Japanese Friend").

The most foundational concepts of any philosophical system, such as God, Being, Absolute, Spirit, Beauty, or Love, are not definable within these systems. Each discipline has its own primary concepts, such as wisdom in philosophy, soul or mind in psychology, and word in linguistics, which are subject to infinitions. In fact, any system of thinking has at its basis certain concepts that cannot be defined within its framework but are used to define other concepts derived from them. This is an example of a philosophical synthesis: on the basis of the existing concept of definition, by analyzing and problematizing, i.e. critically examining its elements, the notion of infinition is constructed.

2. Synthesis of judgments. Every act of analysis contains the possibility and condition of a new synthesis. Where there is a possibility of breaking a judgment into elements, there also exists a possibility of new judgments, a new combination of elements and, therefore, a new domain of thought and speech. For instance, the judgment "stupidity is a vice" can be treated analytically, in the spirit of George Moore, i.e. as equivalent to such judgments as "I have a negative attitude towards stupidity," or "Stupidity evokes negative emotions in me." The synthetic approach to this judgment, however, positions it as a potential foundation for other, alternative and more informative, "wondrous" judgments (cf. Aristotle's idea expressed in Metaphysics about philosophy born out of wonderment).

Let us create a possible sequence of questions and alternative judgments regarding the statement "Stupidity is a vice." Is stupidity always a vice, or can it be considered, in certain cases, a virtue? If intelligence can be exercised for a 
sophisticated justification of a vice, then can innocence serve as a justification of stupidity? If stupidity is sometimes used as a means to a virtuous goal, can it then itself be considered a virtue? Mikhail Saltykov-Shchedrin, a prominent Russian satiric writer of the nineteenth century, coined a remarkable moral term that has come into general usage in Russian: "blagoglupost" (blago + glupost', meaning "virtuous + stupidity"), which can be conveyed by the English neologism "virtupidity." "Virtupidity" is well-intentioned stupidity, highsounding nonsense, or pompous triviality.

Let us take our interrogation to the next level. If stupidity, even only in an ironic sense, can be a virtue, can baseness or meanness be virtuous, as well? Can we speak about "well-intentioned meanness"? Can we speak not only of "virtupidity," but also "benemalence" (from Latin bene, meaning "well" and malus, meaning "bad"; cf. "benevolence" and "malice") as "well-intentioned meanness"? "Benemalence" appears at first sight to be a dubious oxymoron. Lack of intelligence can go hand-in-hand with good intentions, but can the same be said about the malicious and perverse intentions? Can one betray, rape, and blaspheme while having good intentions? The answer is "yes," as evidenced by the examples ranging from the Grand Inquisitor in Dostoevsky's The Brothers Karamazov to the exemplary pioneer Pavlik Morozov, a Soviet official hero who became notorious for denouncing and betraying his father.

Thus, as a trivial subject of analysis, the judgment "stupidity is a vice" can set up grounds for a synthesis of non-trivial, thought-provoking judgments and new word formations, such as "virtupidity" and "benemalence." Language synthesis can be formally operationalized by the symbol $\div$ as the sign of logical bifurcation, i.e. an alternative emerging from the analysis of the aforementioned judgment. The elements of the judgment which precede the sign $\div$ are viewed as variables, whereas their alternatives or variations that follow are the new judgments:

Stupidity is a vice (a trivial judgment).

Problematization:

Stupidity can be $\div$ a vice (but may not be).

Stupidity can be $\div$ a virtue (under certain circumstances).

Synthesis:

One of the conditions of virtue is a good intention.

Stupidity can be the product of good intentions: "Virtupidity."

Meanness can be the product of good intentions: "Benemalence."

Every element of any judgment can be questioned and substituted by another one, generating a new judgment. For instance, if the elements $a, b$, and $c$ can be 
isolated in a judgment as a result of analysis, their synthesis generates the combinations $a c b, b c a, c b a$, and $b a c$, i.e. a new thought, a mental object yet to be cognized, requiring interpretation, and a new act of analysis to be followed by a new synthesis.

Gottfried Leibniz considered the art of synthesis to be more important than that of analysis. For him, synthesis is defined as the algebra of qualities, or combinatorics which deals with forms of objects or formulas of the Universe, i.e. the quality in general, for these formulas are the result of the combination of the initial elements $a, b$, $c$, etc., and this science is different from algebra, which manipulates formulas as they apply to the quantity. ${ }^{7}$

3. Synthesis of the ethical postulate: a diamond rule. Another example is synthesis on a larger scale: not one concept or judgment, but an ethical rule, or a postulate, or a maxim. I shall proceed from the golden rule of morality, which was independently formulated by Confucius, the Jewish sage Hillel, and Jesus in the Sermon on the Mount: "In everything, do to others what you would have them do to you" (Matthew 7:12). To find a proper way to treat others, you should put yourself in the place of someone else.

An analysis of this commandment leads to the separation of the ethical subject and object, "the self" and "the other," but the relationship between them is presumed to be completely reversible. How X wants $\mathrm{Y}$ to do to him, let $\mathrm{X}$ do to $\mathrm{Y}$.

But $\mathrm{X}$ and $\mathrm{Y}$ are different persons with dissimilar abilities and dissimilar needs. Therefore, it is permissible to synthesize a different rule: let everyone use their greatest abilities to fulfill the greatest needs of other people. Do what others need most and what no one can do better than you. If you are a violinist by your gift and calling, then playing the violin rather than chopping wood is the fulfillment of your moral duty, contrary to what the unenlightened masses or totalitarian regimes presume, willingly using the golden rule for levelling people. The Russian poet Marina Tsvetaeva, forced to emigrate and to do mechanical labor, remarked in her diary: "I am not a parasite, because I work and I want nothing else but to work: but my own work, not somebody else's." In this case, this is to compose one's own verses, not to translate those composed by others.

Thus, I propose a postulate that does not annul the golden rule, but rather sets a diamond of an individual gift in its "golden frame": Do that good to others that nobody can do better than you. From this perspective, the best action is

7 Gottfried W. Leibniz, "On Universal Synthesis and Analysis, or the Art of Discovery and Judgment," in Philosophical Papers and Letters, ed. L.E. Loemker, The New Synthese Historical Library (Texts and Studies in the History of Philosophy) vol 2. (Dordrecht: Springer, 1989), 234. 
that which corresponds to the needs of the largest number and the capacities of the smallest number of people. The first criterion is the "golden" universality of a moral act, while the second criterion focuses on its "diamond-like" uniqueness. By questioning one of the elements of the golden rule (reversibility of the subject and the object), we get another, diamond one, as an answer.

4. Synthesis of a discipline. Horrorology. "Civilization studies" or "cultural studies" — an academically established discipline taught at many universitiesexplores various aspects of civilization: from history to science, from art to technology. Over the past decades, especially since the terrorist attacks of 2001 in New York, civilization revealed a property that previously was not so obvious: its growing fragility. I do not mean military forces and weapons that had always been designed for destruction; rather, I refer to the hidden selfdestructive potential of civilization itself. The more complex our urban constructions and communication systems are, the more fragile and vulnerable civilization becomes.

Goethe anticipated this bitter irony of civilization in the second part of Faust. Faust believes that he creates a dam and pushes the sea away from the shores to build a city for the free people, whereas Mephistopheles, who allegedly is carrying out this cherished plan of Faust, has something completely different in mind: to drive as many people as possible to the seashore for their eventual absorption by the sea. This hidden Mephistophelian irony can be seen in all the noble endeavors of Faust; similarly, the same self-destructive irony can be perceived in all daring endeavors of civilization.

Therefore, the study of civilization must be problematized - and supplemented with a discipline that examines its own subversive, shadow side. I conditionally call this discipline "horrorology," a rather dissonant term, as it describes the potential horror that is hidden in the allegedly most peaceful and prosperous creations of civilization: from architecture and aviation to medicine and computing. The higher the skyscrapers, the more powerful the aircraft - the easier it is to send these latter against the former and by mutual collision destroy both. As the terrorist act of September 11, 2001 showed, no special weapon against civilization is needed; civilization provides a range of weapons that can be used against itself. In fact, any artefact can become a weapon - for example, prescription drugs that can be deadly and addictive, or a computer program that is easy to reprogram so as to create chaos in communication systems. So many forms of the most advanced technologies can put humanity at risk that practically any of them deserves its own horrological study. For instance, the Internet, with myriad viruses spreading throughout computer networks, or artificial intelligence is capable of mentally subordinating and eventually destroying its human creators. 
If the fear of pollution-civilization's threat to nature-haunted the second half of the twentieth century, then the twenty-first century may fall prey to the horror: the threats of civilization to itself. Ecology, as the primary concern of humanity, is succeeded by horrology that explores civilization as a system of traps and self-exploding devices, and humankind as a hostage of its own creations. Horrology as a discipline is the reverse of all other disciplines that study civilization. It is a negative science of civilization: hence nega-technology, nega-architecture, nega-sociology, nega-politics, and nega-aesthetics as branches of horrology. Everything studied by other disciplines as positive attributes and structural properties of civilization, horrology studies as the grounds of its self-destruction.

This is an example of the synthesis of a new discipline from those elements of which the study of civilization is made. Through the analysis of civilization, we can problematize those "reversible" elements that can easily turn every creative act into a destructive one.

\section{Part II: How a Philosophy of Synthesis Can Transform the World}

Numerous universes might have been botched and bungled throughout an eternity, ere this system was struck out; much labor lost, many fruitless trials made, and a slow but continual improvement carried out during infinite ages in the art of world-making.

David Hume

\subsection{Synthesis as Transformation}

The philosophy of synthesis includes at least three levels: objective, systematic and transformative. The first level is a synthesis of new mental objects, of those conceptual (logical, semantic, linguistic) elements from which a new term, concept, rule, or discipline is composed (as described in Part 1). The second is metasynthesis, a shift from concrete, targeted interventions and innovations, such as a new concept or discipline, to a systematic construction of alternative pictures of the world, to the synthesis of a whole system of new methods and disciplines. This level is considered in a number of my works, to which, due to the length limitations of this article, I simply refer the reader. ${ }^{8}$ The third level

8 See Mikhail Epstein, A Philosophy of the Possible: Modalities in Thought and Culture, trans. from Russian by Vern W. McGee and Marina Eskina (Boston, Leiden et al.: Brill Academic / Rodopi [Value Inquiry Book Series], 2019), 365 pp.; Mikhail Epstein, The Transformative 
is transformative: moving beyond the limits of philosophical thinking as such towards its synthesis with those practices-technical, cultural, artistic, communicative - that determine the life of society.

1. To form new concepts (terms, rules, disciplines);

2. $\quad$ to systematize the methods of their generation;

3. and to direct them toward the transformation of certain spheres of being: such is the threefold task of the philosophy of synthesis, the sequence of its steps.

Philosophy must determine for itself those methods of action that are specific to it, in contrast to science and technology, politics and art. What is the practical benefit of philosophical synthesis for contemporary technocentric society? Is philosophy doomed to be enclosed in the academic sphere of research and teaching? Or, while remaining faithful to its tradition and its vocation, but using a synthetic methodology, can it powerfully influence the path of social development, as the driving force of civilization, which it was at the time of Plato and Aristotle, Kant and Hegel? In this second section, I will discuss the vocation of philosophy in the twenty-first century, the ways of its engagement with social and intellectual movements and advanced sciences and technologies.

The direction that philosophy clearly took after the Kant's "Copernican" revolution was the strengthening of practical reason, with the aim of active transformation of the world. This was expressed in the famous eleventh thesis of Karl Marx: "Philosophers have hitherto only interpreted the world in various ways; the point is to change it" ("Theses on Feuerbach"). The thesis calls directly for the transition of philosophy from theory to practice, but a frightening asymmetry is hidden in Marx's formulation: "in various ways" refers only to "interpret," but not to "change." Changing the world uniformly, according to only one plan, means exposing it to the risk of devastating consequences, as the totalitarian outcomes of Marxism in the twentieth century make abundantly clear. The philosophy of the twenty-first century, learning the sad lesson of transformism reduced to militant uniformism, should be prepared to follow the call to "change," only adding to it "in various ways." That is, acting pluralistically, increasing rather than reducing diversity, moving in different directions through the multiplicity of alternative philosophical practices.

Humanities: A Manifesto, trans and ed. by Igor Kliukanov (New York and London: Bloomsbury Academic, 2012. 318 p.; Mikhail Epstein, After the Future: The Paradoxes of Postmodernism and Contemporary Russian Culture, trans with introd. by A. Miller-Pogacar (Amherst: U of Massachusetts P, 1995). 392 pp. 

Alternatives

Philosophy is distinct from other fields of inquiry by its focus on the most fundamental truths about the world as such, in its entirety, as a generic unit of thinking. Arthur Schopenhauer exclaimed: "The world, the world, asses! this is the problem of philosophy, the world and nothing else!"9

Furthermore, metaphysics is commonly defined as the most general branch of philosophy that deals with the nature and structure of the world as a whole. Of all philosophical disciplines (including epistemology, logic, ethics, and aesthetics), metaphysics appears to be the least practical as it addresses the broadest questions regarding "being as such" or "the first causes of things." Thus, metaphysics can serve as a useful testing ground for the examination of the practical applications of philosophy. If metaphysics can be used as an engineering tool and a site for practical construction, then philosophy in principle has the potential to change the world which it studies.

What are then these entities that we call worlds, and can we use this term in the plural? A world is everything that exists within one set of laws and is united by the interaction of its parts according to these laws. A most graphic specimen of a world as a single unit would be Narnia by C.S. Lewis, Middle-Earth by J.R.R. Tolkien or any sufficiently developed, immersive computer game. In this way, the first task that the creators of computer games should solve is a metaphysical one: what are the initial parameters of the virtual world in which the action takes place, how many dimensions are there, how does time flow and space unfold, how many actions, steps, blows are permitted to the gamers according to the conditions of their life, and what is considered a condition of death?

If the foundational unit of metaphysical thinking is a world as whole, metaphysics was traditionally set apart from more specific, positivistic disciplines discussing particular aspects of the world. In order to be positive and practical, a discipline has to compare various manifestations of generic laws and properties: for example, various substances and elements (chemistry), organisms (biology), or languages (linguistics). Metaphysics, however, has had at its disposal only one world - the one in which we live. Respectively, philosophers debated over what constitutes the beginning or the first principle of this world. Is it composed of water or fire (Thales or Heraclitus)? Which is preeminent - a universal or an individual (Realism or Nominalism)? Is the world ideal or material in its foundations (Hegel or Marx)? These philosophies-however brilliantly

9 A note of Schopenhauer from his manuscript. Quoted in W. Schirmacher, "Schopenhauers Wirkung: Ein Philosoph wird neu gelesen," Prisma 2, (1989), 25. 
espoused and internally coherent-all remained speculative in that they simply extracted various qualities from the same single world and hypostasized them into general principles, while the world itself remained unchanged.

Now, with the assumption of a multiplicity of worlds in contemporary physics and with the proliferation of simulated worlds in digital technologies, we can look at the range of possible applications of metaphysics differently. Jon Turney identifies three types of computerized worlds: (1) mirror worlds that are ultra-detailed models of actual worlds, such as Google Earth; (2) augmented realities where information comes through artificial devices, such as glasses or wired contact lenses; (3) immersive virtual environments, or fully realized virtual worlds, where you can send your computer-controlled avatar. As information technology progresses from mirror worlds to immersive worlds, which encompass self-contained universes in them, metaphysics will get a better ground for the realization of its world-forming visions..$^{10}$

Any computer game, any virtual world contains the properties of "worldness," which forms a specific subject and concern of metaphysics. Moreover, the scale of such "little worlds" is growing rapidly, from the most primitive action game to Second Life, the design-your-own-avatar online world launched in 2003 , and five years later populated by fifteen million people from one hundred countries, who can participate in individual and group activities, creating and trading items of virtual property. This territory has its own houses, businesses, laws, monetary units (lindens that can be exchanged for real dollars). The gross domestic product of Second Life in 2015 alone reached half a billion dollars (more than in some real countries). This is not just about a new transcontinental and transnational territory, but an alternative universe that potentially has its own ontology and logic, its own laws of space and time, chance and fate, its own metaphysical matrix, which is laid at the basis of its technical construction and software.

Whenever we are talking about the whole world, philosophical categories inevitably come into its description, because their specific content is precisely the worldness of the world. With that in mind, why not turn our thoughts to the next possible stage, when virtual technology will be able to produce something like Tlön, a world from Jorge Luis Borges' story Tlön, Uqbar, Orbis Tertius? In order to describe this world in its worldness, which is based in thought only, Borges has to resort to philosophical arguments and refer to thinkers of the past:

10 Jon Turney, The Rough Guide to the Future (London: Rough Guides, 2010), 306-07. 
Hume noted for all time that Berkeley's arguments did not admit the slightest refutation, nor did they cause the slightest conviction. This dictum is entirely correct in its application to the earth, but entirely false in Tlön. The nations of this planet are congenitally idealist. Their language and the derivations of their language — religion, letters, metaphysicsall presuppose idealism. The world for them is not a concourse of objects in space; it is a heterogeneous series of independent acts. ... [T] he men of this planet conceive the universe as a series of mental processes which do not develop in space but successively in time. Spinoza ascribes to his inexhaustible divinity the attributes of extension and thought; no one in Tlön would understand [this] juxtaposition (1983, pp. 8-9).

We can see how the philosophical ideas of Hume, Berkeley, and Spinoza turn out to be indispensable when considering what would make one world, Tlön, so different from our familiar Earth. This example shows how certain metaphysical assumptions, idealistic in this case, are incorporated in the construction of possible worlds and thus may have a direct impact on the technologies that produce these worlds. Inventors of computer games must first of all set metaphysical parameters for the world in which action will take place. To that end, the following questions must be addressed: how many dimensions does the world contain? What is the nature of time and space in it, and do they constitute one indivisible continuum? What are the relationships between subject and object, and cause and effect? How many moves or hits is each avatar allowed? And what constitute the conditions for each avatar's death or disappearance from the game?

But in order to synthesize a new world, not just in fiction or in a computer game, we have to analyze and to problematize the existing world, to question its foundations and major parameters. Does a world need to be made of physical substances or can it be composed of actions and events and thus described by verbs more adequately than by nouns? Does a living entity need to be mortal or is there a mechanism in its genetic and informational setup that can provide for its practical immortality? Is the capacity to think and produce ideas inexorably linked to the brain or are there other potential vehicles of intelligence? It is difficult to problematize the entire world, the only form of life and the only biological mind that for millennia were uniquely given and known to us. But this is precisely what contemporary science is attempting to do: to problematize the existing world and its most fundamental laws. And this is precisely what contemporary technology strives to do: to synthesize new forms of life and intelligence on the basis of their deep analysis and problematization. 


\subsection{New Relationships of Philosophy and Technology: Collaboration in World-Making}

What is thus brought to light is a new relationship between philosophy and the advanced technologies that I call onto-technologies, because they change the foundations of being and the way in which we experience it. In the past, technology was preoccupied with material particulars, while taking care of concrete human needs, such as food, shelter, and transportation. Philosophy, in its turn, was preoccupied with big ideas, the first principles, essences, and universals. Technology used to be utilitarian, while philosophy was speculative. Today, technology and philosophy are moving ever closer towards each other: the power of technology is extended to the fundamental properties of the universe, while philosophy becomes increasingly active in its ability to define and change these properties. Technologies of the late twentieth and especially the early twenty-first centuries are no longer applied tools, but fundamental technologies making transformative advances into the micro- and macro-worlds, including the structure of the brain and DNA. Such advances make it possible for us to penetrate into the very foundations of being, potentially changing its original parameters or setting up parameters for new kinds of being. Ontotechnology has the power to create a new spatio-temporal continuum, a new sensory environment and modes of its perception (like in the virtual cocoon), along with new kinds of organisms and new forms of intelligence. Nanotechnologies provide the means for the production of any object of desirable qualities and proportions from the elementary particles of matter. Humans are becoming increasingly skilful and successful in the art of world-making. As a result, technology is now moving not away from, but towards, metaphysics; this way, the two of them are meeting at the very core of being, where the principles traditionally studied by philosophy can be changed by technology.

A new synthesis of philosophy and technology is taking the form of technosophia: a technically armed philosophy or philosophically oriented technology. Technosophia establishes the first principles not only in theoretical thought, but also in practical action through alternative forms of matter, life, and mind. With recent breakthroughs in physics, cosmology, genetics, and computer technologies, worldness as the primary interest of metaphysics is now expanded into a multiverse in its multiple forms and alternative branches. With the advent of the multiverse, metaphysics ceases to be a discipline that speculates about the foundations of one world. Instead, it becomes a practical discipline of constructing worlds with various properties, laws, and universals.

Analytic philosophy, which is committed only to the analysis of texts, splitting them into increasingly thin, hair-like notions, is not ready for the solution and even the formulation of such technosophical problems. On the contrary, 
the philosophy of synthesis can become an integral part of the synthetic methodology of science, as outlined by Christopher Langton, the founder of synthetic biology as the theory and practice of artificial life: "Part of what artificial life is all about, and part of the broader scheme that I just call synthetic biology in general, is probing beyond, pushing beyond the envelope of what occurred naturally."11 John Horgan argues, moreover, that at the limits of contemporary science, such a synthetic methodology offers new horizons and possibilities:

Science had obviously made enormous progress by breaking things up into pieces and studying those pieces. But that methodology provided only limited understanding of higher-level phenomena, which were created to a large extent through historical accidents. One could transcend those limitations, however, through a synthetic methodology, in which the basic components of existence were put together in new ways in computers to explore what might have happened or could have happened. ${ }^{12}$

New digital technologies stimulate the development of new methodologies that look not so much for the units of analysis at their boundaries- "atoms" in its field, so to speak — as for such methods of synthesizing them that would broaden the very field of the phenomena under study. Similarly, "synthetic metaphysics" is capable of synthesizing worlds possessing various sets of laws and universals. This perspective involves high-level programming that will model diverse relationships between determinism and indeterminism, or regularity and chance, and other world-building categories. It is possible to construct existentialist and essentialist, materialist and idealist worlds, those of "to be" and "to have," and worlds with various numbers of spatial dimensions and with the flow of time in reverse. We can imagine and potentially implement various virtual realities, for example, the Thalesian and Heraclitean worlds, or the Spinozian and Hegelian worlds. These "watery," "fiery," pantheist or panlogical worlds have their own metaphysical truth and value. Why should we exclude one for the sake of another and reduce the scale and wealth of worldness to one single world?

Using the synthetic "metaworld" matrix, we will be able not only to experiment with the properties of existing metaphysical systems, but also to construct and test new ones. Along with Kantian, Nietzschean, Whiteheadian, and

\footnotetext{
11 John Horgan, The End of Science: Facing the Limits Of Knowledge In The Twilight of the Scientific Age, new ed. (New York: Basic Books, 2015), 199.

12 John Horgan, 200.
} 
Heideggerian worlds, the worlds of yet undescribed qualities could be synthesized experimentally by the modification and combination of diverse parameters. This will transform the entire area of metaphysics into an experimental and constructive branch of knowledge, a humanistic technology that will explore the conditions of various worlds in comparative perspective. The MetaWorld, as a program, will be regulated by knobs/categories, such as "causality," "chance," "event," “action," "dialogue," "matter," “objectivity," "perception," and "selfness" - all of which could be adjusted to different levels of intensity. Rather than the escapism so leveled at those who engage in virtual worlds, one positive "side effect" of such a program would be that by experimenting through the avatars with conditions of numerous worlds, users will develop their better self-awareness and understanding of the real world in which they live.

In fact, in the construction of a virtual world, programmers, engineers, and web designers are all invited to follow in the footsteps of the philosopher, who, as a demiurge of this particular world, formulates its foundational laws to be subsequently enacted technologically into material reality by other specialists. If a philosopher withdraws from this foundational act of thinking "world-wise," then a computer specialist, a software engineer, a game designer and entertainer will inadvertently take upon themselves the role of a philosopher, because a world, even within a primitive game, cannot exist without a certain metaphysics as a system of laws and universals. However, web wizards or game designers certainly are not philosophers; that is why the worlds produced in their workshops are metaphysically so plain and trivial. Those who are genuine philosophers by vocation and education must fill this huge professional niche formed by the accelerated processes of world-making across so many disciplines and occupations.

Some university departments of computing and informational technologies already collaborate with history departments in producing games with historical content, for example, games set in the Elizabethan era or World War II. One can foresee philosophy departments following this example and engaging in strategic decisions about the nature of virtual worlds in the making. Simulated worlds increasingly become intrinsically philosophical as information technologies become more advanced and broaden the scope of their application from material details to the worldness of the world.

Syntheticism - the theory and practice of constructing new worlds and beings-promises to become a direction in philosophy that appears to be more potent and congruous with the advanced technologies of today than any other philosophical "-ism" of the past. Syntheticism is a philosophy of emerging worlds that, based on certain metaphysical matrices, can be implemented by using new information technologies, nanotechnologies, bio-technologies and 
neuro-technologies. A turn from analysis to synthesis is exigent for philosophy if it does not want to turn completely into the scholastic history of philosophy and still aspires to be relevant in the future/for the future.

\subsection{A New Vocation for Philosophy}

Previously, when there was only one world at our disposal, philosophy had to stay a speculative, abstract science. With the development of computer technology and the physical and mathematical arguments for the multiverse, the possibility of practical construction of other worlds opens up, and philosophy for the first time in history finds its practical destination and becomes a supertechnology for the first day of creation.

In this light, technological progress prepares a new role for the philosopher as a metaphysical engineer or a world designer. In the past, the philosopher pronounced the last word about the world, consummating it in thought. For instance, G.W.F. Hegel was fond of repeating the maxim that "the owl of Minerva spreads its wings only with the falling of the dusk."13 In the world of tomorrow, the philosopher will more closely resemble a skylark or even a rooster, proclaiming the dawn of a new creative day. The twenty-first century introduces, at least potentially, alternative varieties of life and intelligence, such as the enhancement of brain capacity with the help of artificial devices and the exploration of holes and tunnels in a space and time continuum. Philosophy, therefore, is no longer mere speculation about the first principles, but an experiment in the conceptual production of multiple worlds-be it the creation of a computer game or a parallel universe with the quality of worldness.

The features of the new stage in the movement of thought are clarified by comparison with those results of world-historical development that are reflected in Hegel's system of absolute idealism. According to Hegel, philosophy completes the works of the absolute idea of self-development and selfknowledge through the worlds of nature and history:

The present standpoint of philosophy is that the Idea is known in its necessity; the sides of its diremption, Nature and Spirit, are each of them recognized as representing the totality of the Idea [...] The ultimate aim and business of philosophy is to reconcile thought or the Notion with reality [...] To this point the World-spirit has come, and each stage has its own form in the true system of Philosophy; nothing is lost, all principles are preserved, since Philosophy in its final aspect is the totality of forms.

13 G.W.F Hegel, Philosophy of Right, trans. T.M. Knox (Oxford: Oxford U P, 1967), 13. 
This concrete idea is the result of the strivings of spirit during almost twenty-five centuries of earnest work to become objective to itself, to know itself $[\ldots]^{14}$

Now, two hundred years after this exhaustive statement, it becomes clear that the history of philosophy is far from consummation. It was only the prehistory of philosophy, its speculative, interpretive stage, whereas now philosophy can enter a truly transformative stage when it opens perspectives on inexhaustible potentials of thinking in the creation of new worlds. Therefore, we can rephrase Hegel in the following way:

The current stage of philosophy reveals its potential to transcend the limits of nature and history. The goal and aspiration of philosophy is to go beyond reality and to conceive new forms of being even before scientists, engineers and other practitioners of positive disciplines can engage in them... The "world spirit" has tested itself in the cognition of reality as it is and has entered the realm of the conceivable-thinkable-possible. Each form of future finds in philosophy its preliminary way of understanding and projection. Philosophy becomes the starting point of experimental work on the radical renewal of being and the creative design of new worlds. This idea is the result of the efforts of the spirit to become objective for itself, to know itself as the beginning of the existing world-in order to lay the foundations for previously non-existent worlds.

From multiple interpretations of one world, philosophy moves on to multiple initiations of different worlds. Philosophy is not at the end, but at the beginning of those forms of matter and being that do not fit into reality and reveal their energy and potentiality in constructive excess, in the embryos of new existences. Just as an engineer is a producer of mechanisms; an artist of paintings, and a politician of institutions and laws; so too is a philosopher a producer of worlds. His professional duty is the expansion of worldness, the creation of universals that enhance the universe into multiverse. He is called upon to know, in the Hegelian sense, the rational in the real, not in order to "justify" reality as it is, but to find the super-real in reason itself and call upon it to create new kinds of being.

14 G.W.F. Hegel, Lectures on the History of Philosophy. Section Three: Recent German Philosophy E. Final Result. https://www.marxists.org/reference/archive/hegel/works/hp/ hpfinal.htm. 
The twentieth century was an age of grandiose physical experiments, but the twenty-first century promises to become a laboratory of even more largescale metaphysical experiments related to free will, the role of chance, the problem of possible worlds, and the paradoxes of twins, doubles, and clones. Physical experiments turn metaphysical when the conditions are ripe for radical technological transformations, like the synthesis of substances and objects with desired properties at the nanolevel or modifications of the genome and creation of new types of organisms. For example, cloning is not just biological or genetic experience; it is an experiment on the relation of human personality to the body, on the identity or difference of individuals in case of genetic identity. Michio Kaku, for example, sees the issue of our doubles, or clones in the parallel quantum worlds, as one of the great ethical and metaphysical concerns: “Are we responsible for our clone's actions? In a quantum universe, we would have an infinite number of quantum clones. Since some of our quantum clones might perform acts of evil, are we then responsible for them? Does our soul suffer for the transgressions of our quantum clones?"15

Similar problems may emerge with our digital avatars or the new power of the brain-computer interface. For instance, am I responsible for the actions of an individual who is genetically identical to myself? Or, with the creation of wireless links between human brains and external electronics, how can my uncontrollable thoughts impact the surrounding world? If my brain is enhanced by the prostheses that transmit the energy of neural signals directly to mighty factory-like machines, this enormously increases my responsibility for the contents of my thinking as compared with the time when it was impenetrably constrained within the cranium.

Therefore, one cannot agree with the pessimistic assertions of Richard Rorty that the opinions of philosophers on how consciousness relates to the brain or what place values occupy in the world of facts, or how determinism and free will can be reconciled, are not of interest to most modern intellectuals. The result was, in Richard Rorty's judgment, the cultural marginalization of philosophy, which is why the profession has become largely irrelevant to wider public discourse:

This consensus among the intellectuals has moved philosophy to the margins of culture. Such controversies as those between Russell and Bergson, Heidegger and Cassirer, Carnap and Quine, Ayer and Austin, Habermas and Gadamer, and Fodor and Davidson, have had no resonance

15 Michio Kaku, Parallel Worlds: The Science of Alternative Universes and Our Future in the Cosmos (London: Penguin Books, 2006), 353. 
outside the borders of philosophy departments. Philosophers' explanations of how the mind is related to the brain, or of how there can be a place of value in a world of fact, or of how free will and mechanism can be reconciled, do not intrigue most contemporary intellectuals. These problems, preserved in amber as the textbook "problems of philosophy," still capture the imagination of some bright students. But no one would claim that discussion of them is central to intellectual life. Solving these very problems was all-important for contemporaries of Spinoza, but when today's philosophy professors insist that they are "perennial," or that they remain "fundamental," nobody listens. Most intellectuals of our day brush aside claims that our social practices require philosophical foundations with the same impatience as when similar claims are made for religion. ${ }^{16}$

This is a tragic situation for philosophy: the more precise it attempts to be (partly by using analytic instruments), the more irrelevant it becomes. The point is not that the list of socially "irrelevant" discussions is fraught with the names of analytic philosophers. Even more deeply metaphysically grounded thinkers, like Bergson and Heidegger, if read through analytic lenses, lose their relevance. The very status of philosophy as the inquiry of the most fundamental truths about the existing world is faltering. Who cares! New worlds proliferate around us and appear to be almost as feasible as this one, and by far more interesting, imaginative and intriguing. Let physics and economy study the existing world on empirical grounds. Yet philosophy — especially metaphysicsis called to something more ambitious: to become the experimental ground for the production of other worlds, universes and universals. The opinion of philosophers on the nature of brain may be not as relevant as that of neuroscientists and neurosurgeons, but the properly philosophical question about "how the mind is related to the brain" is now more relevant than ever before because its solution, or rather the variety of solutions, will have a direct impact on the future of human mind and brain relations and thus, it bears on our own fate. Society is not interested in philosophical speculations on what is and how it is because this information can be obtained from more reliable scientific sources. Society is interested in philosophy inasmuch as it can offer bright visions and models of possible, contingent, necessary, inspiring, challenging worlds, in various formats: cinematic, digital, virtual, physical, cosmological,

16 Richard Rorty, “Universalist Grandeur, Romantic Profundity, Humanist Finitude," Lecture at University of Pécs in Hungary, 3 May 2004, https://books.google.com/books?id=koJqf7i ItdoC\&pg=PA24\&lpg=PA24\&dq. 
mathematical, biological, ecological, genetic, cognitive, psychic, linguistic, and aesthetic formats. Our contemporaries, including intellectuals, do not want from philosophy more meticulous research but rather more grand-scale inspiration. They want to experience how it feels to live in a world with numerous dimensions, with higher or lower degree of physical and social determinism. They want to experience what it is like to be a bat or an overman, a tree or a star. They want to expand the worldness of their experience, the scale of their feelings, thoughts, words and actions. Philosophy enters the epoch of extended modalities: not only what is, but what might be, what needs to be, what is desirable and what is thinkable. ${ }^{17}$

Thus, philosophical problems now acquire even more practical meaning than ever before, precisely because of the tremendous expansion of the capabilities of science and technology, leading to the formulation of more daring, unorthodox metaphysical schemes, or rather opportunities. No wonder Albert Einstein, in his "Remarks on Bertrand Russell's Theory of Knowledge" noted: "The present difficulties of his science force the physicist to come to grips with philosophical problems to a greater degree than was the case with earlier generations." ${ }^{18}$ Ironically, it is the physicist, Einstein, who criticizes the philosopher, Russell, for the latter's, inherited from Hume, "fateful 'fear of metaphysics' [...] which has come to be a malady of contemporary empiricist philosophizing." ${ }^{19}$ It is fair to substitute here "empiricist" for "analytic" as Russell was a more quintessential representative of analytic philosophy than of empiricism. Precisely because physics, cosmology, biology, computer science, and cognitive science reach the foundations and boundaries of the existing universe, these sciences are inherently growing more philosophical. If academic philosophers, including representatives of the analytic tradition, intently avoid these "grand, too grand" issues, out of "fear of metaphysics," then scientists such as David Bohm, Roger Penrose, Stephen Hawking, John Barrow, Paul Davis, Frank Tipler, Ray Kurzweil, Francis Collins, Michio Kaku, Max Tegmark, Lee Smolin, Andrei Linde and many others will take the initiative. As a

17 These multiple modalities of philosophical thinking, in the past, in the present and in the future, are broadly discussed in my book: Mikhail Epstein, A Philosophy of the Possible: Modalities in Thought and Culture, trans. from Russian by Vern W. McGee and Marina Eskina (Boston, Leiden et al.: Brill Academic/ Rodopi [Value Inquiry Book Series], 2019.

18 Albert Einstein, "Remarks on Bertrand Russell's Theory of Knowledge"in The Philosophy of Bertrand Russel, ed. Paul Arthur Schilpp (Open Court Publishing,1944), 280, https:// www.academia.edu/38132327/Albert_Einstein_-_Remarks_on_Bertrand_Russell_s_ Theory_of_Knowledge. 
result, questions themselves do not cease to be deeply philosophical, similar to those over which Pythagoras, Plato, Descartes, Kant, and Hegel were struggling. Philosophical questions persist and are even sharpened and enhanced, but in the absence of interest from professional philosophers, they are transferred to the jurisdiction of physicists, mathematicians, biologists, and cybernetics, who effectively turn out to be more genuine heirs of great metaphysical traditions than employees of the departments of analytic philosophy.

In conclusion, the foundational principles of existence, formerly considered predetermined and unchangeable, today are problematized by science and transformed by technology into metaphysically challenging models of new worldwide realities. With this transformative turn, not a single aspect of the philosophical heritage will be lost or neglected in this new technosophical field. All knowledge proceeding from past systems and schools of thought can be reemployed in the problematization of the existing world and conceptual design of alternative worlds.

Metaphysics applied to the art of world-making is just one example of how philosophy can find a new vocation in the age of advanced technologies. Ontology and epistemology, logic, ethics and aesthetics, philosophy of science and language - all philosophical disciplines are also quite potent to provide models for world-scale transformative actions. If philosophy wants to return to the center of intellectual life, it should not only become a philosophy of synthesis, but also itself form a synthesis with the most advanced technical, informational, biogenetic practices of the twenty-first century.

\section{Works Cited}

Ammerman, Robert, ed. Classics of Analytic Philosophy. Indianapolis and Cambridge: Hackett, 1965 .

Borges, Jorge Luis. Labyrinths. Selected Stories \& Other Writings. New York: Modern Library, 1983 .

Einstein, Albert. "Remarks on Bertrand Russell's Theory of Knowledge." In The Philosophy of Bertrand Russell, edited by Paul Arthur Schlipp. Open Court Publishing (1944), https://www.academia.edu/38132327/Albert_Einstein_-_Remarks_on_Bertra nd_Russell_s_Theory_of_Knowledge.

Epstein, Mikhail. A Philosophy of the Possible: Modalities in Thought and Culture. Translated from Russian by Vern W. McGee and Marina Eskina. Boston, Leiden et al.: Brill Academic/Rodopi [Value Inquiry Book Series], 2019.

Epstein, Mikhail. The Transformative Humanities: A Manifesto. Translated and edited by Igor Klyukanov. New York and London: Bloomsbury Academic, 2012. 
Epstein, Mikhail. After the Future: The Paradoxes of Postmodernism and Contemporary Russian Culture. Translated with an introduction by A. Miller-Pogacar. Amherst: U of Massachusetts P, 1995 .

Hegel, G.W.F. Philosophy of Right. Translated by T.M. Knox. Oxford: Oxford UP, 1967.

Hegel, G.W.F. Lectures on the History of Philosophy. Section Three: Recent German Philosophy E. Final Result, https://www.marxists.org/reference/archive/hegel/works/ hp/hpfinal.htm.

- Please provide publication year for this reference.

Horgan, John. The End of Science: Facing the Limits of Knowledge in the Twilight of the Scientific Age. New ed., New York: Basic Books, 2015.

Kaku, M. Parallel Worlds: The Science of Alternative Universes and Our Future in the Cosmos. London: Penguin Books, 2006.

Kant, Immanuel. Prolegomena to Any Future Metaphysics, https://books.google.com/ books?id=WAw3DAAAQBAJ\&pg=PA785\&lpg=PA785\&dq.

Leibniz, Gottfried Wilhelm. Philosophical Papers and Letters. The New Synthese Historical Library (Texts and Studies in the History of Philosophy), vol 2. Ed. by Loemker, L.E. Dordrecht: Springer, 1989.

Rorty, Richard. "Universalist Grandeur, Romantic Profundity, Humanist Finitude," Lecture at the University of Pécs in Hungary, 3 May 2004, https://books.google.com/ books?id=koJqf7iltdoC\& pg=PA24\&lpg=PA24\&dq.

Russell, Bertrand. Logic and Knowledge: Essays 1901-1950, London: George Allen and Unwin, 1956.

Schirmacher W., "Schopenhauers Wirkung: Ein Philosoph wird neu gelesen," Prisma 2, 1989 .

Stanford Encyclopedia of Philosophy, https://plato.stanford.edu/entries/analysis/ sı.html\# Alexander.

Turney, Jon. The Rough Guide to the Future. London: Rough Guides, 2010. 